\title{
Low-intensity extracorporeal shock wave therapy for III B chronic pelvic pain syndrome
}

\author{
Guizhong Li, Libo Man \\ Department of Urology, Beijing Jishuitan Hospital, Beijing 100035, China \\ Contributions: (I) Conception and design: All authors; (II) Administrative support: L Man; (III) Provision of study materials or patients: All authors; \\ (IV) Collection and assembly of data: G Li; (V) Data analysis and interpretation: All authors; (VI) Manuscript writing: All authors; (VII) Final \\ approval of manuscript: All authors. \\ Correspondence to: Libo Man, MD. Department of Urology, Beijing Jishuitan Hospital, Xinjiekou East Street, West District, Beijing 100035, China. \\ Email: lee_gz99@163.com.
}

Background: To analyze the efficiency of low-intensity shock wave therapy (LI-ESWT) for patients with III B chronic pelvic pain syndrome (CPPS).

Methods: The study included an uncontrolled population of 32 patients who had suffered with CPPS for $\geq 3$ months. LI-ESWT was performed without anesthesia via a perineal approach. The operation was carried out in four weeks by administering 12,000 shock waves. Using the Visual Analog Scale (VAS) and NIHdeveloped Chronic Prostatitis Symptom Index (NIH-CPSI), subsequent tests were performed at 1, 2, 4, and 12 weeks after the first LI-ESWT session.

Results: All patients who received the four week course as treatment responded actively on the pain VAS and the NIH-CPSI, and both were significantly improved $(\mathrm{P}<0.05)$. Compared with the baseline parameters, the NIHCPSI total score and VAS exhibited substantial improvement at 4 and 12 weeks, where a total improvement at four weeks was reached. It is easy and safe to perform LI-ESWT without anesthesia on an outpatient basis.

Conclusions: LI-ESWT should be regarded as a promising new therapy for CPPS, as it is convenient to perform without any side-effects.

Keywords: Chronic pelvic pain syndrome (CPPS); chronic abacterial prostatitis; shock waves

Submitted Sep 27, 2019. Accepted for publication Mar 27, 2020.

doi: $10.21037 /$ tau.2020.04.07

View this article at: http://dx.doi.org/10.21037/tau.2020.04.07

\section{Introduction}

Chronic pelvic pain syndrome (CPPS) is considered a regular urological disorder (1). The incidence is stated to be about $15 \%$ (2). There are several symptoms of CPPS, such as erectile dysfunction (ED) and pain in the prostate, perineal, and suprapubic regions, which may last for more than three months (3). The patients usually suffer from a lot of pain and restrictions, which are like those after a heart attack, angina pectoris, and Crohn's disease (4).

There are currently no causal or standardized therapeutic approaches to CPPS. Anti-inflammatory agents, analgesics, antibiotics, $\alpha$-receptor blockers, and $5 \alpha$-reductase inhibitors are reported to be used separately or in combination $(5,6)$, but there is no convincing evidence to demonstrate the efficacy of each treatment type. Consequently, non-drug treatment options have received increased attention. Lowintensity extracorporeal shock wave therapy [low-intensity extracorporeal shock wave therapy (LI-ESWT)] has so far been used to treat musculoskeletal disorders (7), male ED (8), non-healing wounds (9), and myocardial infarction (10). This study will focus on evaluating the effectiveness and safety of LI-ESWT on patients with CPPS.

\section{Methods}

\section{Inclusion and exclusion criteria}

Patients with CPPS refractory to the traditional 3 -As therapy (antibiotics, alpha-blockers, and anti- 
Table 1 The inclusion and exclusion criteria

\begin{tabular}{ll}
\hline Inclusion criteria & Exclusion criteria \\
\hline Patients who had type IIIB prostatitis/CPPS for more than & Patients with perineal anatomical abnormalities, uncorrected hormone \\
3 months, took a combination of at least one course lipophilic & abnormalities, significant coagulopathy, neurological abnormalities, \\
antibiotic, simple analgesia and alpha blocker, and other & unstable psychiatric disorders, history of extensive pelvic surgery or \\
traditional modalities of CPPS treatment did not affect them & irradiation, prostate cancer, and clinically significant medical diseases \\
\hline
\end{tabular}

CPPS, chronic pelvic pain syndrome.

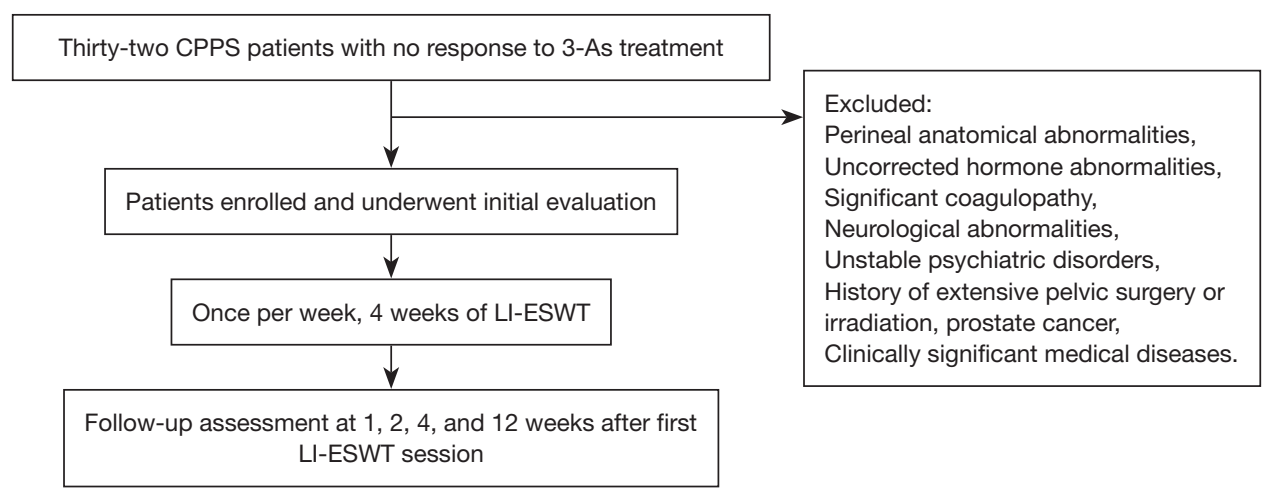

Figure 1 Low-intensity extracorporeal shock wave therapy for chronic pelvic pain syndrome: flow chart. CPPS, chronic pelvic pain syndrome; LI-ESWT, low-intensity extracorporeal shock wave therapy.

inflammatories) were enrolled from Beijing Jishuitan Hospital between May 2018 and July 2019. Participants gave informed consent before the study. The local ethics committee approved the study. The study inclusion and exclusion criteria are seen in Table 1.

\section{Treatment protocol}

The patients received LI-ESWT treatment once a week for four weeks in an outpatient setting without local or systemic anesthesia. At each therapy session, 3,000 impulses were applied on the perineum at 6 different anatomical sites, with a total energy flow density of $0.25 \mathrm{~mJ} / \mathrm{mm}^{2}, 3 \mathrm{~Hz}$. After every 500 pulses, the location of the shock wave transducer was changed to virtually scan the entire area of the prostate and pelvic floor. In the supine position, LI-ESWT was performed. The duration of treatment for each participant was $18 \mathrm{~min}$. An electro-pneumatic shock wave unit with a shock wave source (MASTERPULS, MP100, Storz Medical, Tägerwilen, Switzerland) was used for this study.

\section{Evaluation of outcomes}

The grade of pain was measured using a Visual Analog Scale
(VAS, 0-10). Validated questionnaires [specific complaints with the NIH chronic Prostatitis Symptom Index (CPSI)] were used to investigate the CPPS-related complaints. The follow-up assessments were carried out at 1, 2, 4, and 12 weeks after the first LI-ESWT session. Any adverse effects associated with LI-ESWT were recorded during the follow-up (Figure 1).

\section{Statistical analysis}

Methods of descriptive analysis were used to check the data sets. Quantitative data were expressed as means \pm standard deviations (SD). Mann-Whitney $\mathrm{U}$ test was used to analyze the statistical differences. $\mathrm{P}<0.05$ was considered statistically significant. All statistical analyses were performed using SPSS version 16.0 (SPSS Inc., Chicago, IL, USA).

\section{Results}

Thirty-two patients were included, with a mean age of $36 \pm 13$ years. The mean CPPS history was 33 months (range, 6-36 months). After four weeks of a course of treatment, all of the patients took the pain VAS and the NIH-CPSI, and both were significantly reduced $(\mathrm{P}<0.05$; Table 2$)$. 
Table 2 Change of clinical symptoms after LI-ESWT

\begin{tabular}{lccccc}
\hline & \multicolumn{4}{c}{ Timepoint } \\
\cline { 2 - 5 } Sample, weeks & Baseline & Week 1 & Week 2 & Week 4 & Week 12 \\
\hline Pain score (items 1-4) & $12.43 \pm 5.40$ & $10.71 \pm 4.86$ & $9.86 \pm 4.05$ & $5.43 \pm 3.67^{\mathrm{a}}$ & $7.43 \pm 4.18^{\mathrm{a}}$ \\
Urinary score (items 5-6) & $4.57 \pm 3.76$ & $4.14 \pm 3.3$ & $3.71 \pm 3.27$ & $2.86 \pm 2.51$ & $3.43 \pm 3.13$ \\
QoL (items 7-9) & $9.14 \pm 2.38$ & $9 \pm 3.09$ & $8.71 \pm 3.27$ & $7.86 \pm 3.57$ & $8.71 \pm 3.17$ \\
NIH-CPSI (items 1-9) & $26.14 \pm 9.26$ & $23.86 \pm 8.51$ & $22.29 \pm 7.46$ & $16.14 \pm 6.09^{\mathrm{a}}$ & $19.57 \pm 7.31^{\mathrm{a}}$ \\
VAS & $6.14 \pm 2.86$ & $5.29 \pm 2.92$ & $4.86 \pm 2.25$ & $3 \pm 1.84^{\mathrm{a}}$ & $4 \pm 1.66^{\mathrm{a}}$ \\
\hline
\end{tabular}

a, statistically significant difference compared with the first values between corresponding groups. VAS, Visual Analog Scale; QoL, quality of life; NIH-CPSI, National Institutes of Health Chronic Prostatitis Symptom Index; LI-ESWT, low-intensity extracorporeal shock wave therapy.

For each domain, the NIH-CPSI has been evaluated as shown above. The score of pain domain, as well as the total score, showed significant improvement at week 4, and the treatment effect could be preserved until week $12(\mathrm{P}<0.05)$.

Compared with baseline parameters such as NIH-CPSI total score and VAS, the NIH-CPSI total score and VAS showed significant improvement at weeks 4 and 12, and the highest change was reached at week 4 . Meanwhile, the other parameters showed the maximum effect at 4 weeks but a slight deterioration at week 12. No significant side effects were observed, and it is unnecessary for any type of analgesia during the whole course of treatment.

\section{Discussion}

There are only hypothetical models for the pathogenesis of CPPS so far. The pathophysiology of CPPS has not yet been explained. The manifestations of CPPS often comprise a myofascial pain syndrome, an abnormal tone of the periprostatic musculature, an increasingly visible neurological component, and dysfunctional effects $(11,12)$. There were many complaints associated with the autonomous nervous system and the interplay between smooth and crossstriated muscles. Acute and chronic inflammations involved sympathetic endplate, which may result in the endogenous generation of pain via nociceptive nerve endings and receptors. Furthermore, some psychological stress may result in abnormal electromyographic activity and myofascial pain syndromes (13). Therefore, it is feasible to use myofascial trigger points, cognitive behavioral therapy, and biofeedback and relaxation training to treat those disorders associated with CPPS (14).

Low-intensity extracorporeal shock waves, as a kind of electro-pneumatic shock wave, were transformed into biochemical signals in a process named mechanotransduction, which may hyperstimulate nociceptors and interrupt the former pain memory nerve impulses to achieve 'reprogramming' (15). Furthermore, cavitation bubbles will be generated and popped, which may regenerate secondary energy waves called microjets that lead to additional mechanical forces, increase local microvascularity (16), reduce pain, and help to heal tissue (17).

LI-ESWT has effects on the periprostatic pelvic floor muscles. Consequently, local muscle relaxation may result in the disorder improving due to a reduction in functional muscle shortening (18). This mechanism showed the shortterm effect of the shock waves, since the pain sensation may be prevented relatively transiently without enduring modulation in the sensitivity of the treatment area. In the present study, according to the follow-up of 12 weeks, the VAS and NIH-CPPS were significantly improved, the pain intensity associated with CPPS was reduced by about half, the maximum alleviation was at 4 weeks after the first treatment session, and the pain slightly increased at 12 weeks after LIESWT. However, the therapeutic effect was still significant. As expected, the patients' symptoms were improved via pain reduction by LI-ESWT, which was still valid over several weeks. In our research, the length of follow-up was limited to 12 weeks (16,19-22). The longer-term effect of LI-ESWT may involve some other mechanisms. In previous studies, LIESWT induced cell membrane modifications and functional changes and conducted a series of cell signaling and biological activation processes, such as cell proliferation, angiogenesis, peripheral nerve regeneration, increased cell permeability, and anti-inflammation $(23,24)$.

It is noted that limited studies on LI-ESWT have reported the improvement of CPPS (16,19-22,25-27). In the current investigation, studies reported since 2008 were reviewed and are listed in Table 3. Zimmermann et al. first 


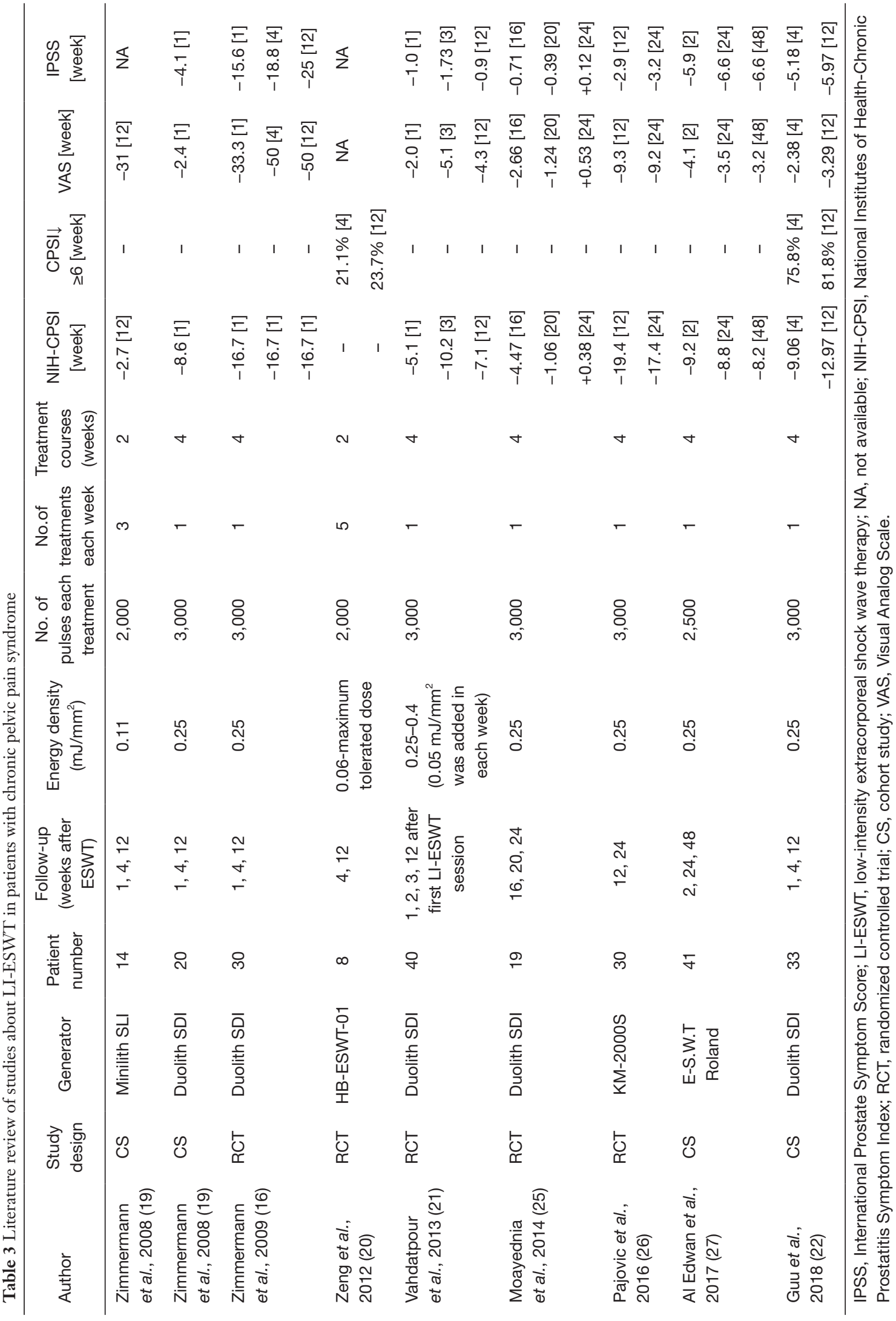


reported using LI-ESWT for the treatment of CPPS in 2008 (19). Five included trials were randomized controlled trials with sham therapy $(16,20,21,25,26)$. However, most of the included trials had small samples. The largest sample included in these reviews was only 41 patients (27). In most of the studies, follow-up was restricted to 12 weeks, while in some studies it was as long as 24 weeks. The long-term effect of LI-ESWT is still equivocal (25-27). According to the literature review in Table 3, both of the cohort and randomized controlled studies revealed statistically significant improvements in NIH-CPSI, QOL, and the pain domain scores after LIESWT in short-term follow-up $(16,19-22,25-27)$.

The weakness of our study was that it employed an open-label clinical trial lacking a controlled group and a small sample size. In our study, the number of shock waves and the energy level were decided empirically. Furthermore, as discussed above, the term of followup was only 12 weeks. The number of treatments, the treatment intervals, and the number of pulses per session was calculated from previous clinical application trials, so it is uncertain which formulation should be used in the treatment protocol. The present mechanisms cannot explain the longer-term effect of LI-ESWT. Compared with week 1 , there was some deterioration in total NIHCPSI, pain, the urinary scores, and QoL at week 24 of follow-up in some studies (25-27).

The strength of our study was that all of our included patients did not achieve satisfactory results from all other traditional modalities of treatments such as combined alphablockers, simple analgesia, and antibiotics. There were no significant side-effects during or after treatment, and it is convenient for the patients to undergo an out-patient treatment. However, it is still necessary to define a sufficient therapeutic protocol such as energy density, probe location, pulse numbers, and session numbers, and to determine crucial predict factors regarding successful response to LIESWT in patients with CPPS.

In conclusion, LI-ESWT may be considered necessary for CPPS treatment, since it is convenient to apply without side effects. For the first time, it is possible to employ LIESWT to provide a rapid and thrifty outpatient therapeutic option for CPPS by using a standard unit as well as a treatment which was time-saving and can be repeated as demanded. A double-blind placebo-controlled study, including a sham treatment and an extended follow-up, is expected for further evaluation of this method.

\section{Acknowledgments}

Funding: This work was supported by the Beijing Municipal Science \& Technology Commission No. Z171100001017133.

\section{Footnote}

Conflicts of Interest: Both authors have completed the ICMJE uniform disclosure form (available at http://dx.doi. org/10.21037/tau.2020.04.07). Both authors report grants from Beijing Municipal Science \& Technology Commission, during the conduct of the study.

Ethical Statement: The authors are accountable for all aspects of the work in ensuring that questions related to the accuracy or integrity of any part of the work are appropriately investigated and resolved. The local ethics committee approved the study (No. 201901-07). Participants gave informed consent before the study.

Open Access Statement: This is an Open Access article distributed in accordance with the Creative Commons Attribution-NonCommercial-NoDerivs 4.0 International License (CC BY-NC-ND 4.0), which permits the noncommercial replication and distribution of the article with the strict proviso that no changes or edits are made and the original work is properly cited (including links to both the formal publication through the relevant DOI and the license). See: https://creativecommons.org/licenses/by-nc-nd/4.0/.

\section{References}

1. Nickel JC. Classification and diagnosis of prostatitis: a gold standard? Andrologia 2003;35:160-7.

2. Mehik A, Hellström P, Lukkarinen O, et al. Epidemiology of prostatitis in Finnish men: a population-based crosssectional study. BJU Int 2000;86:443-8.

3. Nickel JC. Clinical evaluation of the man with chronic prostatitis/chronic pelvic pain syndrome. Urology 2002;60:20-2; discussion 22-3.

4. McNaughton Collins M, Pontari MA, et al. Quality of life is impaired in men with chronic prostatitis: the Chronic Prostatitis Collaborative Research Network. J Gen Intern Med 2001;16:656-62.

5. Krieger JN, Nyberg L Jr, Nickel JC. NIH consensus definition and classification of prostatitis. JAMA 
1999;282:236-7.

6. Weidner W, Anderson RU. Evaluation of acute and chronic bacterial prostatitis and diagnostic management of chronic prostatitis/chronic pelvic pain syndrome with special reference to infection/inflammation. Int J Antimicrob Agents 2008;31 Suppl 1:S91-5.

7. Rassweiler JJ, Knoll T, Köhrmann KU, et al. Shock wave technology and application: an update. Eur Urol 2011;59:784-96.

8. Hayashi D, Kawakami K, Ito K, et al. Low-energy extracorporeal shock wave therapy enhances skin wound healing in diabetic mice: a critical role of endothelial nitric oxide synthase. Wound Repair Regen 2012;20:887-95.

9. Becker M, Goetzenich A, Roehl AB, et al. Myocardial effects of local shock wave therapy in a Langendorff model. Ultrasonics 2014;54:131-6.

10. Hazan-Molina H, Reznick AZ, Kaufman H, et al. Periodontal cytokines profile under orthodontic force and extracorporeal shock wave stimuli in a rat model. J Periodontal Res 2015;50:389-96.

11. Zermann DH, Ishigooka M, Doggweiler R, et al. Neurourological insights into the etiology of genitourinary pain in men. J Urol 1999;161:903-8.

12. Clemens JQ, Nadler RB, Schaeffer AJ, et al. Biofeedback, pelvic floor re-education, and bladder training for male chronic pelvic pain syndrome. Urology 2000;56:951-5.

13. Simons DG. Review of enigmatic MTrPs as a common cause of enigmatic musculoskeletal pain and dysfunction. J Electromyogr Kinesiol 2004;14:95-107.

14. McCracken LM, Turk DC. Behavioral and cognitivebehavioral treatment for chronic pain: outcome, predictors of outcome, and treatment process. Spine (Phila Pa 1976) 2002;27:2564-73.

15. Melzack R, Wall PD. Pain mechanisms: a new theory. Science 1965;150:971-9.

16. Zimmermann R, Cumpanas A, Miclea F, et al. Extracorporeal shock wave therapy for the treatment of chronic pelvic pain syndrome in males: a randomised, double-blind, placebo-controlled study. Eur Urol 2009;56:418-24.

17. Wang CJ, Wang FS, Yang KD, et al. Shock wave therapy induces neovascularization at the tendon-bone junction. A study in rabbits. J Orthop Res 2003;21:984-9.

18. Manganotti P, Amelio E. Long-term effect of shock wave therapy on upper limb hypertonia in patients affected by stroke. Stroke 2005;36:1967-71.

19. Zimmermann R, Cumpanas A, Hoeltl L, et al. Extracorporeal shock-wave therapy for treating chronic pelvic pain syndrome: a feasibility study and the first clinical results. BJU Int 2008;102:976-80.

20. Zeng XY, Liang C, Ye ZQ. Extracorporeal shock wave treatment for non-inflammatory chronic pelvic pain syndrome: a prospective, randomized and sham-controlled study. Chin Med J (Engl) 2012;125:114-8.

21. Vahdatpour B, Alizadeh F, Moayednia A, et al. Efficacy of extracorporeal shock wave therapy for the treatment of chronic pelvic pain syndrome: a randomized, controlled trial. ISRN Urol 2013;2013:972601.

22. Guu SJ, Geng JH, Chao IT, et al. Efficacy of LowIntensity Extracorporeal Shock Wave Therapy on Men With Chronic Pelvic Pain Syndrome Refractory to 3-As Therapy. Am J Mens Health 2018;12:441-52.

23. Liu T, Shindel AW, Lin G, et al. Cellular signaling pathways modulated by low-intensity extracorporeal shock wave therapy. Int J Impot Res 2019;31:170-6.

24. Wang HJ, Cheng JH, Chuang YC. Potential applications of low-energy shock waves in functional urology. Int J Urol 2017;24:573-81.

25. Moayednia A, Haghdani S, Khosrawi S, et al. Longterm effect of extracorporeal shock wave therapy on the treatment of chronic pelvic pain syndrome due to non bacterial prostatitis. J Res Med Sci 2014;19:293-6.

26. Pajovic B, Radojevic N, Dimitrovski A, et al. Comparison of the efficiency of combined extracorporeal shock-wave therapy and triple therapy versus triple therapy itself in Category III B chronic pelvic pain syndrome (CPPS). Aging Male 2016;19:202-7.

27. Al Edwan GM, Muheilan MM, Atta ON. Long term efficacy of extracorporeal shock wave therapy [ESWT] for treatment of refractory chronic abacterial prostatitis. Ann Med Surg (Lond) 2017;14:12-7.
Cite this article as: Li G, Man L. Low-intensity extracorporeal shock wave therapy for III B chronic pelvic pain syndrome. Transl Androl Urol 2020;9(3):1323-1328. doi:10.21037/ tau.2020.04.07 